\title{
Drug Master File
}

National Cancer Institute

\section{Source}

National Cancer Institute. Drug Master File. NCI Thesaurus. Code C70877.

Drug Master File (DMF) is a submission to the Food and Drug Administration (FDA) that may be used to provide confidential detailed information about facilities, processes, or articles used in the manufacturing, processing, packaging, and storing of one or more human drugs. 